JMI Vol. 41 No. 1, Juni 2019

METAL INDONESIA

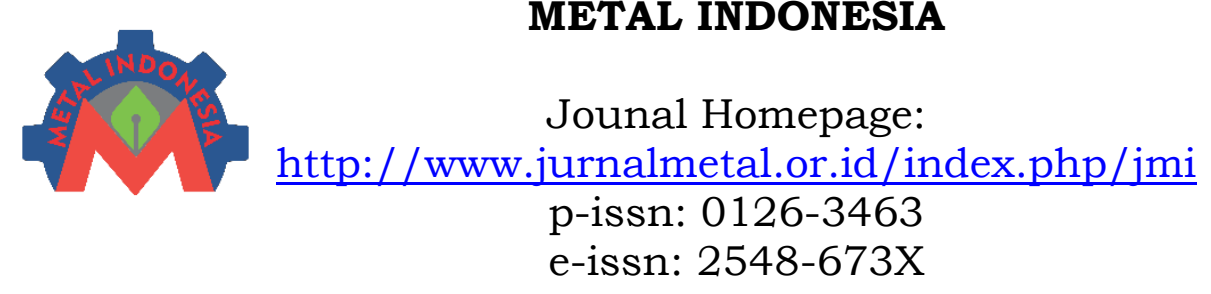

\title{
PEMBUATAN ALAT INJECTION PUMP BERBASIS OTOMASI DI BALAI BESAR LOGAM DAN MESIN
}

\section{MAKING OF INJECTION PUMP BASED ON AUTOMATION IN BALAI BESAR LOGAM DAN MESIN}

\author{
Robby Debriand Rumbara ${ }^{1}$, Mas Sahid BHM ${ }^{2}$, Hendri Siswanto ${ }^{3}$, Mufid Djoko Purwanto ${ }^{4}$ \\ 1,2,3,4 Balai Besar Logam dan Mesin, Kementerian Perindustrian \\ Jl. Sangkuriang No. 12 Bandung 40135 \\ 1'robby-debriand@kemenperin.go.id, ${ }^{2}$ massahid@kemenperin.go.id, \\ ${ }^{3}$ hendrisiswanto@kemenperin.go.id, ${ }^{4}$ mufid@ kemenperin.go.id
}

\begin{abstract}
Abstrak
Injection pump adalah peralatan medis untuk memasukkan cairan obat secara otomatis pada pasien, dikarenakan alat ini masih diimpor maka perlu dibuat prototipe untuk mendukung kemandirian nasional. Prototipe injection pump menggunakan arduino uno sebagai mikrokontroler yang dilengkapi motor penggerak, layar LCD, dan beberapa tombol untuk melakukan pengaturan. Alat ini telah diuji sesuai kondisi injection pump komersial (6 tipe suntikan), yaitu $3 \mathrm{cc}, 5 \mathrm{cc}, 10 \mathrm{cc}, 20 \mathrm{cc}, 30 \mathrm{cc}$ dan $50 \mathrm{cc}$. Prototipe ini dapat berfungsi dengan baik dan dapat memasukkan cairan obat dengan debit $0.1 \mathrm{~mL} / \mathrm{h}$ hingga $999 \mathrm{~mL} / \mathrm{h}$ dengan ketelitian $0.1 \mathrm{~mL}$.
\end{abstract}

Kata kunci: Injection pump, otomatis, arduino uno

\begin{abstract}
Injection pump is a medical equipment for injecting drug fluids into patients automatically, because this equipment is still imported therefore, a prototyping is needed to support the local industry for developing their capability in producing such equipment. The injection pump prototype uses Arduino Uno as a microcontroller equipped with a drive motor, LCD screen, and several buttons to make arrangements. This tool has been tested according to the conditions of a commercial injection pump (6 types of injections) they are $3 c c, 5 c c, 10 c c, 20 c c, 30 c c$ and $50 \mathrm{cc}$. This prototype can work properly and can injecting drug fluids with flowrate of $0.1 \mathrm{cc} / \mathrm{h}$ to $999 \mathrm{cc} / \mathrm{h}$ in $0.1 \mathrm{cc}$ accuracy.
\end{abstract}

Keywords: Injection pump, automatic, Arduino Uno

\section{PENDAHULUAN}

Injection pump merupakan salah satu alat medis yang banyak digunakan oleh unit pelayanan kesehatan yang berfungsi untuk memasukkan cairan obat pada pasien. Kebutuhan injection pump pada tahun 2012 adalah 863 unit dimana hal tersebut di suplai dari 1 produsen lokal dan 25 importir (Kemenkes, 2013).

Berdasarkan kebutuhan injection pump di atas maka permintaan impor alat tersebut dirasakan cukup besar. Di sisi lain, Kementerian Perindustrian telah menyusun roadmap mengenai 10 industri prioritas yang dikembangkan pada tahun 2015 - 2019 termasuk industri farmasi, kosmetik, dan alat kesehatan. Sementara itu, Kementerian Perindustrian juga telah merilis program mengenai pengembangan otomatisasi di dunia industri (industri 4.0).

Balai Besar Logam dan Mesin merupakan satuan kerja di bawah Kementerian 
Perindustrian, bergerak di penelitian dan pengembangan (litbang) logam dan mesin bermaksud menangkap peluang tersebut yang diwujudkan dalam bentuk pembuatan prototipe injection pump menggunakan mikrokontroller Arduino Uno.

Proses pembuatan prototipe ini utamanya adalah meniru peralatan yang sudah tersedia di dunia kesehatan sehingga fitur-fitur pengoperasian alat dan macam-macam tipe suntikan yang dapat digunakan serta standar dunia kesehatan yang dianut. Selanjutnya dilakukan pembuatan desain protototipe. Berdasarkan desain ini dapat diidentifikasi komponen-komponen yang dibutuhkan. Kemudian, dilakukan perakitan (asembling) komponen-komponen tersebut menjadi injection pump.Bagian-bagiannya ditunjukkan seperti pada Gambar 1.

Parameter utama pada prototipe injection pump ini adalah:

-Linier actuator

Berfungsi untuk mendorong suntikan/spuit yang akan menginjeksikan cairan obat. Motor yang digunakan pada prototipe ini adalah motor stepper

- Sistem kontrol

Berfungsi untuk mengatur kecepatan putaran motor penggerak (stepper). Sistem kontrol merupakan integrasi dari perintah keypad, menu di layar LCD, mikrokontroler arduino uno beserta program (software) yang telah dibuat.

- Suntikan/spuit

Berfungsi untuk menyimpan cairan obat yang akan diinjeksikan pada pasien. Variasi suntikan yang digunakan yaitu: $3,5,20,30$, dan $50 \mathrm{cc}$

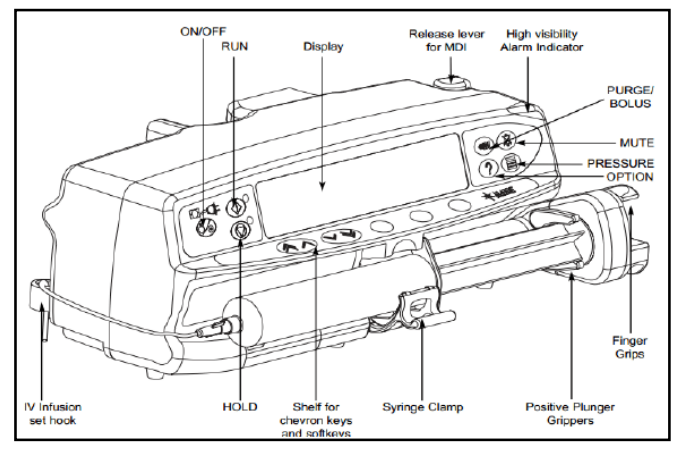

Gambar 1. Bagian injection pump

Sumber gambar: Tyler (2009)

\section{METODOLOGI}

Penelitian ini dilakukan di Balai Besar Logam dan Mesin pada bulan September sampai Desember 2018 yang terdiri atas beberapa tahapan sebagai berikut:
1. Pengumpulan bahan/studi literatur yang berkaitan dengan injection pump, metode kerja, prosedur penggunaan alat, maupun katalog injection pump yang telah dijual umum/bebas.

2. Pembuatan desain prototipe injection pump.

3. Instalasi/asembling beberapa komponen termasuk wiring/penyambungan kabel.

4. Pembuatan program arduino.

5. Proses pengujian; menggunakan peralatan seperti: gelas ukur, stopwatch, beker glass, dan timbangan digital. Pengujian debit cairan yang dihasilkan pada prototipe injection pump dilakukan melalui metode tidak langsung (penimbangan cairan).

\section{Desain Injection Pump}

Desain prototipe injection pump dapat dilihat pada Gambar 2. Secara umum bagian prototipe terdiri atas: casing, tombol perintah (keypad), layar LCD, linier actuator dan spuit/suntikan. Casing prototipe injection pump terbuat dari material acrilyc dengan dimensi 340 x 170 x 109 mm dengan ketebalan 5 mm. Casing terdiri dari 2 bagian yaitu upper casing (penutup atas) dan lower casing (penutup bawah. Casing/penutup dihubungkan dengan engsel pada bagian depan body injection pump.

Upper casing digunakan untuk menyimpan beberapa komponen seperti: linier actuator, tombol keypad/perintah, tombol ON/OFF, tombol switch, layar LCD, dan spuit/suntikan. Sedangkan lower casing digunakan untuk menyimpan komponen seperti power supply, driver motor, arduino kit, dan buzer/alarm.

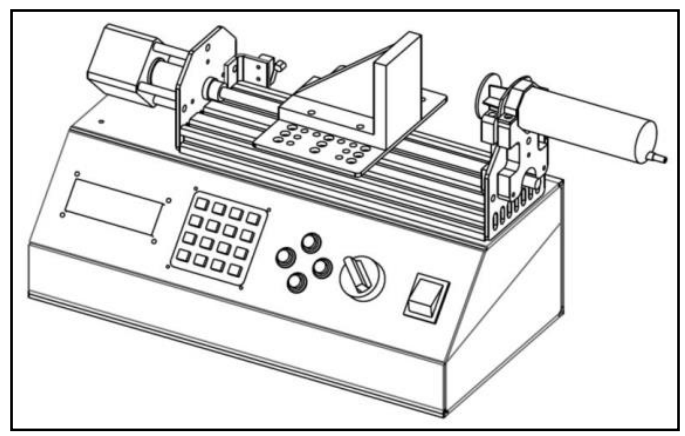

Gambar 2. Desain injection pump

\section{Rancangan Percobaan}

Prinsip kerja dari alat yang akan dibuat adalah apabila tombol POWER ditekan maka layar LCD akan menyala (splash screen) kemudian suntikan/spuit dipasang. Setelah suntikan terpasang dilanjutkan dengan mengatur nilai kecepatan, volume, panjang 
suntikan serta laju aliran. Setelah itu dilanjutkan dengan menekan tombol START maka injection pump akan bekerja. Apabila cairan suntikan telah habis (posisi suntikan/spuit maksimum) maka alarm akan berbunyi dan posisi suntikan akan bergerak mundur pada posisi awal/semula.

Proses perencanaan hubungan antar beberapa komponen injection pump ditunjukkan seperti pada blok diagram berikut (Gambar 3). Komponen injection pump terdiri atas komponen utama (output dan input atau I/O, mikrokontroler) dan komponen pelengkap (driver motor, power supply).

Komponen utama dan pelengkap pada injection pump dapat dijelaskan sebagai berikut: - TS1 (Toogle Switch 1) merupakan komponen input berfungsi untuk memindahkan gerakan motor (maju/mundur)

- KP (Keypad) merupakan komponen input berfungsi untuk memasukkan nilai kecepatan/debit aliran cairan.

- PB1 (Push Button 1) merupakan komponen input yang berfungsi sebagai tombol START maupun menggerakkan injection pump mundur secara manual. PB1 berwarna hijau dan terletak di sebelah kiri.

-PB2 (Push Button 2) merupakan komponen input yang berfungsi sebagai tombol STOP maupun menggerakkan injection pump maju secara manual. PB2 berwarna merah dan terletak di sebelah kanan.

-PB3 (Push Button 3) merupakan komponen input yang berfungsi sebagai tombol CONFIRM untuk melanjutkan ke menu berikutnya. PB3 berwarna biru dan terletak di atas.

-PB4 (Push Button 4) merupakan komponen input yang berfungsi untuk menjalankan injection pump pada mode manual setelah ditekan tombol STOP. PB4 berwarna biru dan terletak di bawah.

-LCD (Layar LCD) merupakan komponen output untuk menampilkan informasi dan input laju aliran injection pump.

-LED(Lampu indicator) merupakan komponen output yang berfungsi sebagai tanda/signal sedang aktif (hijau), bekerja normal (berkedip), dan mengalami gangguan (merah).

-BUZZ (Buzzer/alarm) merupakan komponen output yang berfungsi memberikan tanda pada pengguna bahwa proses injeksi telah selesai maupun mengalami gangguan.
-LS1 (Limit Switch 1) merupakan komponen input yang berfungsi memberikan pengaman bahwa posisi injection pump maksimum sehingga akan mematikan motor stepper.

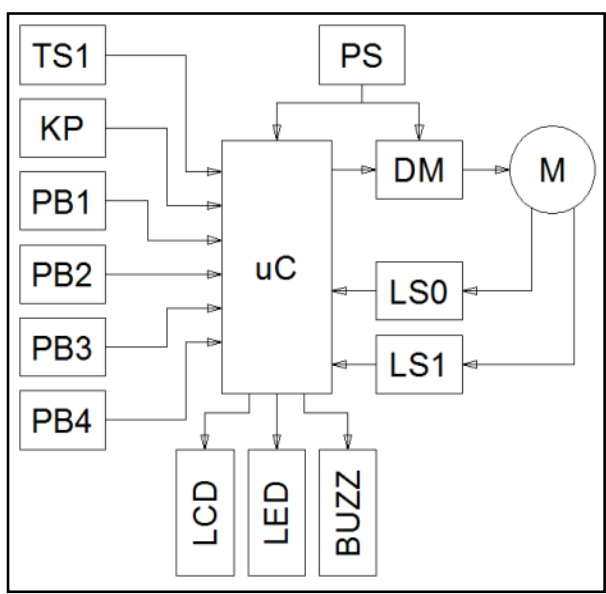

Gambar 3. Rancangan percobaan alat

- LS0 (Limit Switch 0) merupakan komponen input yang berfungsi memberikan pengaman bahwa posisi injection pump minimum sehingga akan mematikan motor stepper.

-DM (Driver Motor) merupakan komponen yang berfungsi untuk mengatur gerakan motor stepper sehingga putaran motor lebih presisi.

-PS (Power Supply) merupakan komponen yang berfungsi untuk mengubah listrik $\mathrm{AC}$ ke DC yang dijadikan sumber daya utama pada mikrokontroler.

-M (Motor stepper) merupakan komponen output yang berfungsi mendorong suntikan/spuit maju (injeksi cairan) maupun mundur (mode manual).

- $\mu \mathrm{C}$ (Mikrokontroller) merupakan komponen elektronika yang berfungsi untuk mengendalikan komponen elektronik lain (proses tunggal) dan sederhana.

\section{Instalasi dan Wiring Diagram}

Prototipe injection pump yang telah dilakukan proses asembling ditunjukkan pada Gambar 4, adapun rangkaian wiring prototipe dapat dilihat pada Gambar 5. Bahasa yang digunakan untuk melakukan program pada mikrokontroler arduino adalah bahasa $\mathrm{C}$. 


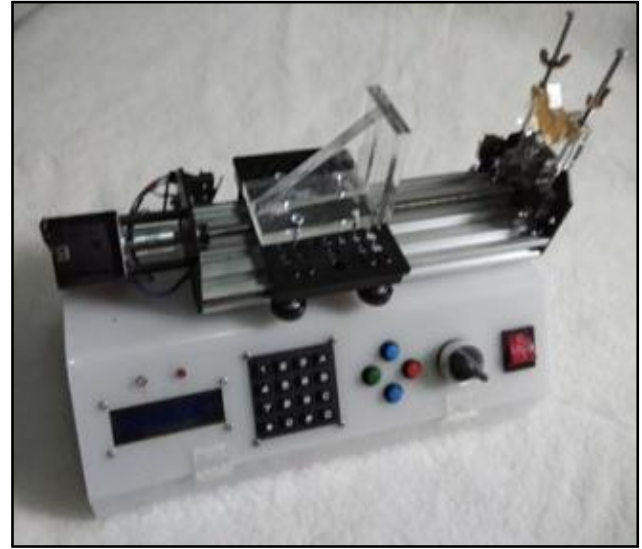

(tampak dari luar)

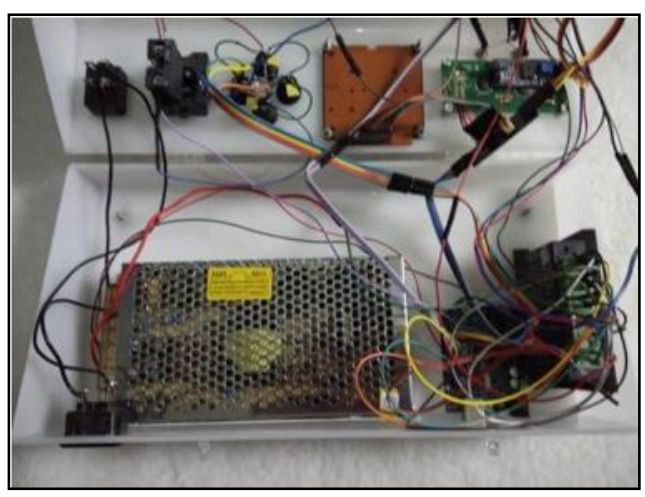

(tampak dari dalam)

Gambar 4. Hasil proses asembling

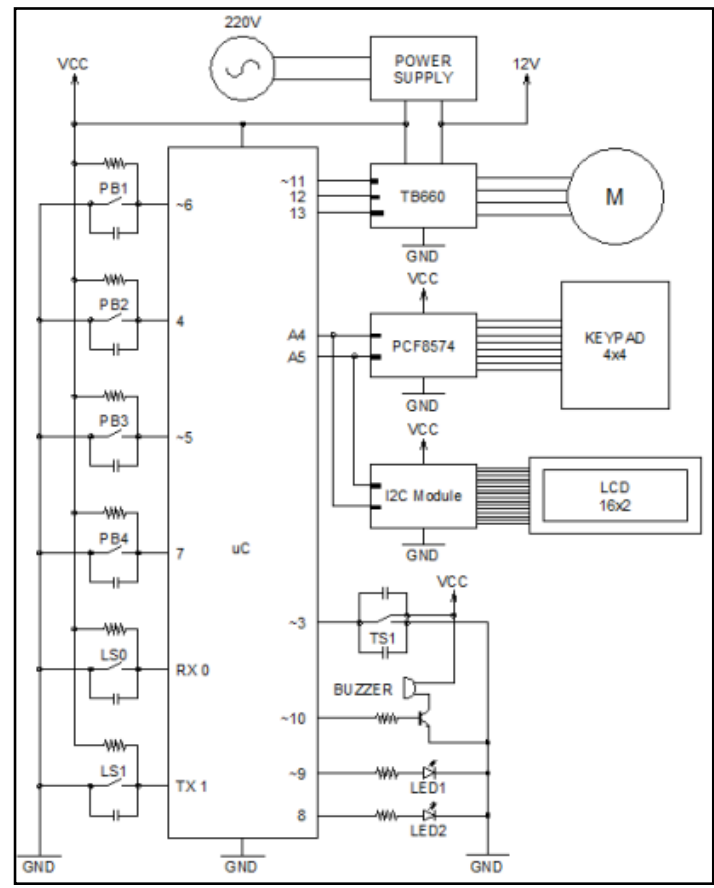

Gambar 5. Wiring injection pump

\section{HASIL DAN PEMBAHASAN}

Sebuah suntikan/spuit yang berisi cairan dan didorong secara manual maupun menggunakan motor listrik akan menghasilkan laju alir/debit tertentu yang memiliki nilai sesuai persamaan berikut:

$$
Q=A \cdot v
$$

dimana

$\mathrm{Q}=$ laju alir atau debit

$\mathrm{A}=$ luas penampang (saluran fluida)

$\mathrm{v}=$ kecepatan aliran

Pada sistem injection pump, kecepatan aliran fluida identik dengan panjang langkah injeksi cairan terhadap waktu injeksi. Namun dikarenakan sistem penggerak yang digunakan adalah motor dan ulir maka berlaku persamaan:

$$
v=\frac{l_{p}}{t_{p}}
$$

dimana

$\mathrm{v}=$ kecepatan aliran

$1_{\mathrm{p}}=$ panjang pitch ulir

$t_{p}=$ waktu revolusi 1 putaran (motor stepper)

Persamaan (1) dan (2) selanjutnya dilakukan subtitusi sehingga diperoleh:

$$
Q=\frac{A \cdot l_{p}}{t_{p}}
$$

Dikarenakan motor penggerak pada injection pump menggunakan motor stepper tipe Nema 17 yang memiliki sudut step $1,8^{0}$ yang memiliki arti yaitu untuk melakukan 1 kali putaran motor diperlukan sinyal step sebanyak 200 sehingga dapat ditulis seperti pada persamaan berikut:

$$
\begin{array}{r}
t_{p}=x . t_{m} \\
t_{p}=200 . t_{m} \ldots \ldots \ldots
\end{array}
$$

dimana

$\mathrm{x}=$ jumlah step dalam 1 kali revolusi $\mathrm{t}_{\mathrm{m}}=$ waktu jeda (mikrokontroler)

Selanjutnya untuk memperoleh persamaan hubungan antara waktu jeda dengan laju alir atau debit yang dihasilkan maka dilakukan subtitusi persamaan (4) ke persamaan (3) sebagai berikut:

$$
Q=\frac{A \cdot l_{p}}{200 \cdot t_{m}}
$$

Sebagai contoh berdasarkan hasil pengujian prototipe injection pump diperoleh data seperti ditunjukkan pada Tabel 1 . Pengujian prototipe injection pump ini dilakukan dengan variasi suntikan/spuit $3 \mathrm{cc}, 5$ cc, $10 \mathrm{cc}, 20 \mathrm{cc}, 30 \mathrm{cc}$ dan $50 \mathrm{cc}$. Setiap ukuran suntikan diberikan 20 variasi waktu jeda pada program arduino yaitu 10 s.d. 100000 mikro second. Setelah dilakukan perhitungan untuk beberapa ukuran suntikan, diperoleh bahwa terdapat perbedaan nilai antara hasil pengujian terhadap hasil perhitungan, maka pada 
persamaan 5 diperlukan penambahan nilai konstanta (k) agar besaran nilai pada program arduino tidak menyimpang jauh terhadap hasil perhitungan. Sehingga persamaan yang akan digunakan pada basic program di arduino mengikuti persamaan (6) sebagai berikut:

$$
Q=\frac{A \cdot l_{p}}{200 \cdot k \cdot t_{m}}
$$

Besar nilai $\mathrm{k}$ untuk masing-masing suntikan telah ditetapkan yaitu: $3 \mathrm{cc}$ (13), 5 cc (14), $10 \mathrm{cc}$ (15), $20 \mathrm{cc}$ (16), $30 \mathrm{cc}$ (15) dan $50 \mathrm{cc}$
$(16,5)$. Setelah dilakukan input nilai $\mathrm{k}$ pada masing-masing suntikan dengan 20 variabel waktu jeda diperoleh nilai error/kesalahan tiga terbesar secara berurutan yaitu:

a. 3 cc: waktu jeda 10, 20 dan $100000 \mu \mathrm{S}$

b. 5 cc: waktu jeda 4000, 20000 dan $10 \mu \mathrm{S}$

c. 10 cc: waktu jeda 10,20 dan $500 \mu \mathrm{S}$

d. 20 cc: waktu jeda 10, 20 dan $50 \mu \mathrm{S}$

e. 30 cc: waktu jeda 10,20 dan $20000 \mu \mathrm{S}$

f. 50 cc: waktu jeda 10,20 dan $1000 \mu \mathrm{S}$

Tabel 1. Hasil Pengujian Injection Pump

\begin{tabular}{|c|c|c|c|c|c|c|c|c|c|c|c|c|c|c|c|c|c|c|}
\hline \multirow{3}{*}{$t_{m}$} & \multicolumn{18}{|c|}{ Volume Suntikan (Spuit) } \\
\hline & \multicolumn{3}{|c|}{$3 \mathrm{cc}$} & \multicolumn{3}{|c|}{$5 \mathrm{cc}$} & \multicolumn{3}{|c|}{$10 \mathrm{cc}$} & \multicolumn{3}{|c|}{$20 \mathrm{cc}$} & \multicolumn{3}{|c|}{ 30cc } & \multicolumn{3}{|c|}{ 50cc } \\
\hline & $t_{\text {uk }}$ & $\mathbf{v}_{\mathbf{u}}$ & $\mathbf{Q}$ & $\mathbf{t}_{\mathbf{u k}}$ & $\mathbf{v u}_{\mathbf{u}}$ & Q & $t_{u k}$ & $\mathbf{v}_{\mathbf{u}}$ & $\mathbf{Q}$ & $t_{\text {uk }}$ & $\mathbf{V}_{\mathbf{u}}$ & $\mathbf{Q}$ & $t_{\text {uk }}$ & $\mathbf{v}_{\mathbf{u}}$ & $\mathbf{Q}$ & $\mathbf{t}_{\mathrm{uk}}$ & $\mathbf{v}_{\mathbf{u}}$ & $\mathbf{Q}$ \\
\hline 10 & 1.6 & 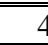 & 9000 & 0.4 & 3 & 27000 & 1.2 & 7 & 21000 & 1.8 & 20 & 40000 & 1.9 & 27 & 51239 & 3.2 & 51 & 57375 \\
\hline 20 & 1. & 3 & 353 & & 9 & 18000 & 2.1 & 9 & 15429 & 2.7 & 20 & 26667 & 3.0 & 28 & 33962 & 4.5 & 55 & 000 \\
\hline 50 & 3.8 & 4 & 790 & 1 & 3 & $\overline{5684}$ & 3.7 & 8 & 7784 & 5.7 & 20 & 12631 & 6.2 & 28 & 16193 & 7.1 & 51 & \\
\hline 100 & 6.8 & 4 & 2118 & 5.6 & 5 & 3214 & 6.9 & 8 & 4174 & 10.1 & 20 & 7129 & 11.5 & 28 & 8762 & 15.2 & 58 & 13737 \\
\hline 200 & 13.7 & $\overline{4}$ & 1051 & 11.1 & 5 & 1622 & 13.6 & 8 & 2118 & 21 & 21 & 3600 & 21 & 27 & 4631 & 23 & 45 & 7043 \\
\hline 300 & 1 & 4 & 727 & 16 & 5 & 1111 & 21.1 & 8 & 1365 & 29.7 & 20 & 2424 & 31.5 & 27 & & 41.5 & 56 & 4858 \\
\hline 400 & & 3 & 434 & & 5 & 845 & 6.7 & 8 & 1079 & 4 & 20 & 1796 & 41.2 & 27 & & & 51 & 3786 \\
\hline 500 & 36.3 & 4 & 397 & 26.9 & 5 & 669 & 25.6 & 7 & 984 & 49.7 & 21 & 1521 & 51.4 & 27 & 1891 & 59.7 & 50 & 3015 \\
\hline 1000 & 64.1 & 4 & 225 & 54.2 & 5 & 332 & 65.9 & 8 & 437 & 101 & 21 & 748 & 97.6 & 26 & 959 & 160 & 51 & 1147 \\
\hline 1500 & 89.8 & 3 & 120 & 79 . & 5 & 226 & 107 & 9 & 303 & 149 & 21 & 508 & 156 & 28 & 646 & & 49 & 997.2 \\
\hline 2000 & 130 & 4 & 111 & 107. & & & 121 & 7 & 209 & 20 & & 358 & 20 & & 471 & & 50 & 751.6 \\
\hline 2500 & 14 & 4 & 102 & & & & 172 & 9 & 187.8 & 24 & 20 & 298 & 200 & & 384 & 20 & 50 & 608.5 \\
\hline 3000 & 191 & 4 & 75.2 & 168.9 & 5 & 107 & 202 & 7 & 124.7 & 293 & 20 & 246 & 314 & 27 & 310 & 352 & 51 & 521.2 \\
\hline 4000 & 250 & 4 & 57.7 & 224.8 & 4 & 64.1 & 280 & 8 & 103 & 396 & 20 & 182 & 408 & 28 & 247 & 391 & 41 & 377.3 \\
\hline 6000 & 365 & 4 & 39.5 & & 5 & 5 & 410 & 8 & 70.2 & 585 & 19 & 117 & 629 & 29 & 166 & & 49 & 254.2 \\
\hline 10000 & 604 & 3 & 17.9 & 546.5 & 5 & 32.9 & 649 & 8 & 44.4 & 1067 & 22 & 74.2 & 955 & 26 & 98 & & 34 & 148.6 \\
\hline 15000 & & 3 & 12.3 & 828.2 & 5 & 21.7 & 839 & 6 & 25.7 & 1495 & 20 & 48.2 & 1443 & 26 & $\begin{array}{l}64.8 \\
\end{array}$ & 1716 & 48 & 100.7 \\
\hline 20000 & 1017 & 3 & 10.6 & \begin{tabular}{|l|}
1085 \\
\end{tabular} & 4 & 13.3 & 1113 & 6 & 19.4 & 1878 & 20 & 38.3 & 1566 & 26 & 59.8 & 2400 & \begin{tabular}{l|}
51 \\
\end{tabular} & 76.5 \\
\hline 50000 & 3535 & 4 & 4.1 & 2709 & 5 & 6.6 & \begin{tabular}{|l|}
2851 \\
\end{tabular} & 7 & 8.8 & 4280 & 17 & 14.3 & 3737 & 19 & 18.3 & 4278 & 34 & 28.6 \\
\hline 100000 & \begin{tabular}{|l|l}
4877 \\
\end{tabular} & 2 & 1.5 & 5322 & 4 & 2.7 & \begin{tabular}{|l|l|}
4570 \\
\end{tabular} & 5 & 30 & 8903 & 18 & 7.3 & 5158 & 16 & 112 & \begin{tabular}{|l|}
9649 \\
\end{tabular} & 40 & 14.9 \\
\hline
\end{tabular}

Keterangan:

- Diameter dalamsuntikanmasing-masingadalah: $3 \mathrm{cc}(9,6 \mathrm{~mm}), 5 \mathrm{cc}(12,5 \mathrm{~mm}), 10 \mathrm{cc}(15 \mathrm{~mm}), 20 \mathrm{cc}(20,3 \mathrm{~mm}), 30 \mathrm{cc}(22,7$ $\mathrm{mm}), 50 \mathrm{cc}(29,5 \mathrm{~mm})$

-Panjangsuntikanmasing-masingyaitu: $3 \mathrm{cc}(55 \mathrm{~mm}), 5 \mathrm{cc}(58 \mathrm{~mm}), 10 \mathrm{cc}(76 \mathrm{~mm}), 20 \mathrm{cc}(90 \mathrm{~mm}), 30 \mathrm{cc}(102,5 \mathrm{~mm}), 50 \mathrm{cc}$ $(104,5 \mathrm{~mm})$

$\mathbf{t}_{\mathbf{m}}=$ waktu jeda di program arduino $(\mu \mathrm{S}) ; \mathbf{t}_{\mathbf{u k}}=$ waktu pengukuran pengujian $(\mathrm{S}) ; \mathbf{v}_{\mathbf{u}}=$ volume cairan hasil pengujian $(\mathrm{gr}) ; \mathbf{Q}$ $=$ debit hasil pengujian $(\mathrm{ml} / \mathrm{h})$

\section{KESIMPULAN}

Pembuatan prototipe injection pump di Balai Besar Logam dan Mesin Tahun 2018 dengan laju alir/debit $0.1 \mathrm{~mL} / \mathrm{h}$ hingga 999 $\mathrm{mL} / \mathrm{h}$ dengan ketelitian $0.1 \mathrm{~mL}$ telah selesai dilakukan, namun untuk mendapatkan debit minimum $0.1 \mathrm{~mL} / \mathrm{h}$ untuk setiap ukuran suntikan, diperlukan penyesuain pada program arduino sebagai berikut:

a. Ukuran suntikan $3 \mathrm{cc}$, setting waktu jeda $\left(\mathbf{t}_{\mathbf{m}}\right)$ adalah 2 detik

b. Ukuran suntikan $5 \mathrm{cc}$, setting waktu jeda $\left(\mathbf{t}_{\mathbf{m}}\right)$ adalah 3,18 detik

c. Ukuran suntikan $10 \mathrm{cc}$, setting waktu jeda $\left(\mathbf{t}_{\mathbf{m}}\right)$ adalah 4,2 detik d. Ukuran suntikan $20 \mathrm{cc}$, setting waktu jeda $\left(\mathbf{t}_{\mathbf{m}}\right)$ adalah 7,54 detik

e. Ukuran suntikan $30 \mathrm{cc}$, setting waktu jeda $\left(\mathbf{t}_{\mathbf{m}}\right)$ adalah 9,66 detik

f. Ukuran suntikan $50 \mathrm{cc}$, setting waktu jeda $\left(\mathbf{t}_{\mathbf{m}}\right)$ adalah 14,85 detik.

\section{SARAN}

Prototipe injection pump telah berfungsi dengan baik, akan tetapi alat ini belum dikalibrasi oleh lembaga yang berwenang agar dapat diterima oleh masyarakat luas/ lingkup medis. Selain itu juga diperlukan perhatian yang lebih mendalam mengenai aspek-aspek lain di luar keberfungsian alat, seperti: keselamatan 
dan keamanan serta peraturan maupun undangundang yang berkaitan dengan peralatan medis.

\section{UCAPAN TERIMA KASIH}

Penulis mengucapkan terima kasih Kepala Balai Besar Logam dan Mesin dan Bapak Mufid Djoko Purwanto (Kepala Bidang Penilaian Kesesuian, BBLM) yang telah berkenan untuk memberikan bantuan dan fasilitas untuk mendukung dalm kegiatan penelitian ini.

\section{DAFTAR PUSTAKA}

Alkes, S. (2018, May 7). Alkes info. Retrieved October 16, 2018, from Alkes info Website:https://sentralalkes.com/blog/sy ringe-pump/

Ampall.co,. Ltd. Catalogue Volumetric Infusion Pump IP-7700 Syringe Pump SP-8800. Korea

Arduino. (2018). Arduino. Retrieved October 16, 2018, from www.arduino.cc: https://www.arduino.cc/en/tutorial//

Halim, F. R., Drs. Suwandi, M. \& Dr. Eng. Asep Suhendi, S. M. (2016). Rancangan Bangun Syringe Pump Menggunakan Motor Stepper Berbasis Arduino. EProceeding of Engineering: Vol. 3, No. 2 Agustus 2016

Hikmah, N. F. (2012). Rancang Bangun Syringe Pump Berbasis Mikrokontroler ATMEGA8535 Dilengkapi Deteksi Oklusi. Surabaya: Universitas Erlangga

Kemenkes. 2013. Permenkes No. 86 Tahun 2013. Jakarta: Kemenkes.

Polak, A. (2017). Design and Fabrication of Controllable Syringe Pumps for Microfluidics. Prague: Czech Technical University in Prague

Sulistyanto, P. (2013). Syringe Pump Otomatis Berbasis Microkontroller Arduino Uno. Yogyakarta: Universitas Sanata Dharma

Suprianto. (2015, October 30). http://blog.unnes.ac.id. Retrieved October 16, 2018, from http://blog.unnes.ac.id/antosupri/limitswitch-saklar-pembatas/

Kementerian Kesehatan RI (2017). Sosialisasi Peraturan Perundang-undangan Bidang Kefarmasian dan Alat Kesehatan. Bogor Tyler, I. (2009). Alaris GH Syringe Pump User Manual (pp. 1-34). Rolle, Switzerland 